Screening for depression and anxiety after stroke: developing protocols for use in the community

\author{
IAN I. KNEEBONE, ${ }^{1,2}$, LISA NEFFGEN $^{2}$ \& SARAH PETTYFER ${ }^{1}$
}

${ }^{1}$ Surrey Community Health, Leatherhead, UK

${ }^{2}$ Department of Psychology, University of Surrey, Guildford, UK

Address for correspondence: $\quad$ Dr Ian Kneebone

Haslemere Hospital

Church Lane

Haslemere

SURREY GU27 2BJ

UK

Phone: +44 (0) 1483782360

Fax: $\quad+44(0) 1483782398$

Email: i.kneebone@nhs.net

Key words: Stroke, depression, anxiety, screening, community

Word Count: 2518, excluding abstract, references, implication points, acknowledgements, declaration, figures and tables

Submission Disability and Rehabilitation - Sep 2011

This is the author's version of a work that was accepted for publication in Disability and Rehabilitation. Changes resulting from the publishing process, such as peer review, editing, corrections structural formatting, and other quality control mechanisms may not be reflected in this document. Changes may have been made to this work since it was submitted for publication. A definitive version is s published: Kneebone, I. I., Neffgen, L., \& Pettyfer, S. (2012). Screening for depression and anxiety after stroke: Developing protocols for use in the community. Disability and Rehabilitation, 34, 1114-1120. doi: 10.3109/09638288.2011.636137 


\title{
Screening for depression and anxiety after stroke: developing protocols for use in the community
}

\author{
Abstract \\ Purpose. To develop screening protocols to detect depression and anxiety after stroke \\ in a community setting and train therapists to administer them.
}

Method. Psychologists and a community therapist met to design a system suitable for screening for anxiety and depression in all those with stroke, including people with cognitive and / or communication problems. Other therapists and a local user group were also consulted. Therapists were then trained in the use of the protocols. The ability to enact the protocols was assessed via case vignettes and staff experience, over a month long trial.

Results. It was considered appropriate for community therapists to screen patients and to do this within four weeks of first contact. Two protocols were designed, one for patients without significant communication/cognitive deficits and one for patients with these difficulties. Therapists applied the protocols with accuracy to the case vignettes and rated the training highly. No challenges in applying the protocols in the clinical setting were reported over an initial one-month trial.

Conclusion Two protocols to screen for depression and anxiety after stroke have been developed. These appear feasible for use when trialled via case vignette and in clinical practice. Further research might consider the usefulness of the screens in detecting 
actual clinical disorder and developing better screens to identify anxiety after stroke, particularly in those with a cognitive and / or communication disorder.

\section{Introduction}

Around a third of stroke survivors are depressed at any given time after their stroke [1] and those who have experienced stroke are at approximately a double risk of suicide [2]. Post-stroke depression also appears to have a considerable effect on rehabilitation outcomes. It is associated with poorer functional status [3, 4]) reduced cognitive performance [5], greater physical disability [6, 7], poorer language functioning [7] and even mortality $[8,9]$.

There is evidence to suggest that anxiety is almost as prevalent as depression after stroke. Longitudinal studies find a prevalence rate between $22 \%$ and $28 \%$ in the acute stage and at follow-up $[10,11]$. Given that high anxiety can cause a reduction in concentration, attention and sleep, it is likely its presence impedes stroke rehabilitation. Consistent with this Astrom [10] found that dependence in activities of daily living and a reduced social network were associated with higher anxiety in stroke patients three years following their event.

The effect of depression and anxiety after stroke is not confined to the person who has had the stroke. Caring for someone with stroke is often challenging [12]. It is significant that caregivers rate anxiety and depression in the person with stroke as among the most stressful difficulties [13]. 
Given its prevalence and impact, it is not surprising that screening for depression and attention to anxiety after stroke has been recommended by many agencies including the Royal College of Physicians [14] and the British Psychological Society [15]. Despite the recommendations, however, screening fails to happen for at least a third of patients [16]. Hart and Morris surveyed stroke services to consider professionals compliance with guidelines [17]. They identified a number of barriers to screening including concerns about screening instruments, the time taken to administer them, deficits in knowledge about and skills in administration, uncertainty as to who should perform screening and that screening has not been established as routine. This paper documents the attempt to overcome these barriers by developing protocols to screen for depression and anxiety after stroke and training rehabilitation therapists in their use, in a community rehabilitation setting.

\section{Method}

Community therapy staff initiated contact with the local physical rehabilitation psychology service to consider the development of a feasible screening system to detect psychological distress in patients who had experienced a stroke. A series of meetings between psychology staff (a consultant clinical psychologist and a clinical psychology trainee) and a community therapist (an occupational therapist) were held. Issues considered included what should be screened for, who should screen, when, the instruments that might be used for screening and what should be done depending on the results of the screens. The instruments considered for use were based on those described in two reviews $[18,19]$. The community therapist then liaised with in excess of 15 colleagues to determine whether they had any concerns about the draft protocols 
developed and who they considered could be responsible for administering them. A psychology staff member also asked a local service user group whether they thought the protocols were practical and reasonable to use, including questions about suicidal ideas. The two psychology staff and the community therapist then agreed on the instruments

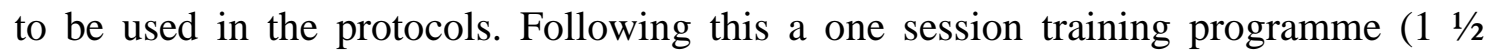
hours) was developed and two groups of community therapists were trained. The training was delivered by two doctoral trainees in clinical psychology, both having graduate membership of the British Psychological Society, a different trainee on each occasion. The trainees were supported by a chartered clinical psychologist with over 20 years experience in working with people who have had a stroke. In addition to specific teaching on the protocols, these sessions included information on anxiety and depression, the nature of these after stroke and how to question patients about suicidal ideation. On completion of the training the therapists' ability to use the protocols was examined via their consideration, in written form, of different patient scenarios and how they would screen with reference to the presentations described. The therapists rated the training in the use of the protocols on a 1 (poor) to 4 (excellent) scale on dimensions of interest, comprehensibility, pace, participation level, preparation of the trainers, handout quality and responsiveness of the trainers to participants training needs. In the month following training the therapists fed back any problems encountered with the screening in clinical practice.

\section{Results}

What should be screened for, who should screen and when should this occur 
On the basis of relevant guidelines and evidence as to their prevalence and impact it was agreed screening should take place for both anxiety and depression. While there is general agreement about screening for these difficulties after stroke, clarity as to who should screen, when and with what instruments varies $[17,19,20]$. As our community therapists are often involved in rehabilitation of stroke patients (indeed some services are dedicated to this diagnostic group) it was considered via consensus they could perform screening. This was consistent with the view nurses and therapists not trained or not practicing in mental health can perform this task [21-23]. It was decided trainees or students should not do the screening unless supervised.

As depression and anxiety can occur anytime post-stroke it was considered screening could occur at any time. Practical considerations from therapists, however, suggested it attempts should be made to achieve screening within four weeks of first contact and screening repeated if concerns arose.

Instruments to be used for screening

It was felt that the screening tools to be utilised should be easy to use and take a relatively short period of time to administer. It was further considered instruments should be suitable for individuals with cognitive and communication disability and preferably have demonstrated reliability, validity, sensitivity and specificity in a stroke sample. Given evidence the nature of depression and anxiety maybe different in older and younger people [24, 25] it was felt important to consider whether different instruments should be used dependent on the age of the patient. Finally it was deemed important that suicidal ideation was considered in the protocols. The instruments 
chosen to be included in the protocols are listed in table 1 alongside details of their specificity and sensitivity.

\section{Insert table 1 about here}

Screening patients without significant communication or cognitive problems

The Patient Health Questionnaire - 9 (PHQ-9) [26] was chosen as the screen for depression for several reasons. Importantly it taps the nine diagnostic symptom criteria that define DSM-IV major depressive disorder (MDD) [27]. It is quick to administer and has been found to have adequate reliability, validity, sensitivity and specificity in a stroke sample, including in those who are older [28]. It was also a measure used by local general practitioners (GPs - family doctors) considered of value in communication of findings. GP familiarity with scores would likely mean they would require less support to understand them and to direct any management based upon them.

The Hospital Anxiety and Depression Scale - Anxiety (HADS-A) [29] was chosen as the screen for anxiety in those without significant cognitive or communication disability. While there is mixed evidence to the use of the HADS-A [18, 30], it remains the only anxiety specific measure validated in stroke samples with published sensitivity and specificity data. A cut off of 6 or more was recommended for the HADS-A, despite some suggestions that it be substantially lower [30]. Support for this cut off was found in a sample considered 4 months after stroke [31], a time frame consistent with likely contact with community services. Unfortunately no research has considered the suitability of the HADS-A for older versus younger patients with stroke. 


\section{Screening patients with significant cognitive and / or communication problems}

The Stroke Aphasic Depression Questionnaire-10 Community (SADQ-10) [32] was considered appropriate for screening for depression in those with cognitive and / or communication problems that preclude administration of the PHQ-9. As it is scale completed by an observer it is suitable for use with this group of patients. Research has demonstrated it to be reliable and valid to screen for depressive symptoms in a community sample [32, 33]. Unfortunately no study has yet considered any differential utility of any observer depression scale for older versus younger stroke survivors.

A literature search failed to identify any measure of anxiety suitable for screening for anxiety after stroke in those with cognitive and/or communication problems. Indeed, no relatively brief observer rating scale was found for anxiety at all. On this account the psychologists involved in the study used their clinical experience and the literature on anxiety to develop a tool to assist therapists to screen, the Behavioural Outcomes of Anxiety (BOA). Table 2 lists the items included in the BOA with reference to their origins in the literature where relevant [27, 34-36]. As the BOA is an un-standardised tool it should be used with caution. Nonetheless it was considered the BOA could be used to start a discussion about anxiety with carers that could identify any significant concerns.

Insert table 2 about here

Screening for suicidal ideas 
In discussion with therapists it was determined questioning regarding suicidal ideas could occur if patients scored above cut-off for depression on any of the measures utilised. As question 9 of the PHQ-9 includes asking patients if they have been bothered by thoughts they 'would be better off dead' it was determined regardless of the overall depression score, any patient scoring $\geq 1$ on this item should be questioned about suicidal ideas. In patients with significant cognitive or communication problems it was acknowledged questioning about this should only be done if the therapist felt it was meaningful to do so. As therapists expressed some concerns about how to question about suicidal ideas, guidance on doing this was developed by the psychologists. Figure 1 lists a sequence of questions suggested as a means by which relevant information might be sought. It was identified that questioning about suicidal ideas should be included in therapist training in use of the protocols.

\section{Insert figure 1 about here}

\section{User consultation}

Generally users were supportive of therapists considering psychological distress via screening as well as of the instruments suggested for this purpose. As therapists had expressed concerns about screening for suicidal ideas this was one point specifically raised in the consultation with the user group. Users supported asking about suicidal ideas: indeed one user indicated they felt it could prove 'a relief' to share such concerns when they were present.

\section{The protocols}


The protocols for screening using the instruments recommended for use with those with and without communication and or cognitive disability are presented in figures 2 and 3. The protocols included information about the screening instruments to be used and when and the course of action available, dependant on the results of the screening. It was considered in the case of a patient disclosing suicidal ideas, immediate action should be taken to protect the patient.

\section{Insert figures 2 and 3 about here}

As can be seen in Figures 2 and 3, the protocols suggest referral on for those patients scoring above cut offs on the screening measures, or for whom concerns are raised (e.g., for anxiety in those with significant cognitive or communications problem where a cut off is not available).

\section{Other issues}

It was determined that the training should emphasise that screening tools do not diagnose depression or anxiety: they merely assess relevant symptoms. Accordingly, it was made clear that an above cut off result does not necessarily indicate a depression/anxiety diagnosis and a below cut off result does not necessarily mean an absence of depression/anxiety. The main use of the screening tools is to prompt for a more complete assessment. In particular it was noted that while cut offs are given, if there is significant concern about a patient referral could occur without the criterion indicated being breached. Specific examples included if patients appeared to exhibiting 
symptoms of panic disorder or had marked a fear of falling with avoidance. It was also considered training should note there were real limits to assessing suicidal ideas and that whether a patient reported these or not, did not necessarily predict their acting. Further it was seen important to re-assure therapists they would be identifying suicidal ideation, not assessing risk. Those to whom they subsequently referred their patients would determine this.

As therapists might potentially feel distressed by the patients' affirmative response to questions about suicide, or indeed other issues raised by the screening, it was determined they should receive guidance on appropriate avenues to elicit support. It was decided a handout on this would be given to all those who were to participate in the screening training session.

\section{Training and trial outcomes}

Eleven therapists (ten occupational therapists and one speech and language therapist) were trained in how to complete the screening. The therapists had between .75 and 24 years of professional experience, $\mathrm{M}=11.5, \mathrm{SD}=6.93$ years, and spent between 5 and $100 \%, M=38.6, \mathrm{SD}=33.25 \%$, of their time working with patients who had suffered stroke. While there was some variation in the order of which therapists chose to administer the screens, all chose the correct tools to administer with respect to the disability described in the case vignettes presented. On average, $84 \%$ of the therapists' ratings of the training were in the "excellent" range for the dimensions of interest, comprehensibility, pace, participation level, preparation of the trainers, handout quality 
and responsiveness of the trainers to participants training needs. No concerns in administering the protocols were received in the month following the training.

\section{Discussion}

Emotional problems are common after stroke and impact on recovery. Protocols to screen for these should increase the chances that such problems are detected and patients receive appropriate interventions. Psychologists working with community therapists and users were able to establish protocols for this purpose that included the provision of strategies to allow the circumstances of those with cognitive and / or communication problems to be taken into account. The protocols appeared feasible when trialled via case vignette and in clinical practice. Barriers to screening have been overcome by developing the protocols, training individuals in their use and making it a routine procedure.

This work extends that which has considered protocols to screen for emotional problems from the in-patient setting [22] to the community. It would be useful for therapists' ability to enact the protocols in clinical practice to be subject to formal audit. Future research might also address the usefulness of the procedures determined in detecting actual clinical disorder and any impact of screening on treatment.

This development has highlighted the relatively poor level of evidence regarding the use of screening measures to detect anxiety after stroke, particularly for those unable to 
complete screens that require language ability. In light of the mixed recommendations in the literature as to cut offs for the HADS anxiety scale in stroke, this should be subject to further investigation. The BOA requires a full assessment of its psychometric properties. Whether different measures should be used to detect anxiety in older versus younger stroke survivors might also be considered, as should the utility of SADQ to detect depression with respect to developmental stage.

\section{Acknowledgements}

We are grateful to the members of the Royal Surrey County Hospital Area Stroke Survivors Working Group, to the participating therapists, and to Kathryn Corson, US Department of Veterans Affairs, Portland, OR, USA.

\section{Declaration of Interest}

The authors report no declaration of interest. 


\section{References}

[1] Hackett ML. Frequency of depression after stroke: a systematic review of observational studies. Stroke 2005;3: 1330-40.

[2] Stenager EN. Suicide in patients with stroke: epidemiological study. Brit Med J 1998;316: 1206-10.

[3] Hermann N, Black SE, Lawrence J, Szekely C, Szalai, JP. The Sunnybrook stroke study: a prospective study of depressive symptoms and functional outcome. Stroke 1998;29: 618-24.

[4] Pohjasvaara T, Vataja R, Leppavuori A, Kaste M, Erkihjuntti T. Depression is an independent predictor of poor long-term functional outcome post-stroke. Europ $\mathrm{J}$ Neurol 200;8: 315-9.

[5] Morris PL, Raphael B, Robinson RG. Clinical depression is associated with impaired recovery from stroke. Med J Australia 1992;157: 239-42.

[6] Dennis M, O’Rourke SM, Lewis S, Sharpe M, Warlow C. Emotional outcomes after stroke: factors associated with poor outcome. J Neurol Neuro Psychiatry 2000;68: 4752.

[7] Parikh RM, Robinson EG, Lipsey J R, Starkstein SE, Federoff JP, Price TR. The impact of post-stroke depression on recovery in activities of daily living over a 2-year follow-up. Arch Neurol 1990;47: 785-9.

[8] House A, Knapp P, Bamford J, Vail A. Mortality at 12 and 24 months after stroke may be associated with depressive symptoms at 1 month. Stroke, 2001;32: 696-701.

[9] Morris PL, Robinson RG, Andrzejewski P, Samuels J, Price TR. Association of depression with 10-year post-stroke mortality. Am J Psychiatry 1993;150: 124-9.

[10] Astrom M. Generalized anxiety disorder in stroke patients: a 3-year longitudinal study. Stroke, 1996;27: 270-5.

[11] De Wit L, Putman K, Baert I, Lincoln NB, Angst F, Beyens H, Bogaerts K, Brinkmann N, Connell L, Dejaeger E, De Weerdt W, Jenni W, Kaske C, Komárek A, Lesaffre E, Leys M, Louckx F, Schuback B, Schupp W, Smit, B, Feys H. Anxiety and depression in the first six months after stroke: a longitudinal, multicentre study. Disabil Rehabil 2008;30: 1858-66.

[12] Simon S, Kumar S. Kendrick T. Cohort study of informal carers of first-time stroke survivors: profile of health and social changes in the first year of care giving. Soc Sci Med 2009;69: 404-10.

[13] Haley WE, Allen JY, Grant JS, Clay OJ, Perkins M, Roth DL. Problems and benefits reported by stroke family caregivers: results from a prospective epidemiological study. Stroke 2009;40: 2129-33. 
[14] Royal College of Physicians. National Clinical Guideline for Stroke ( ${ }^{\text {rd }}$ ed.). London: Royal College of Physicians; 2008.

[15] British Psychological Society. Psychological services for stroke survivors and their families: Briefing paper 19 (Rev ed.). Leicester: the British Psychological Society; 2010.

[16] Royal College of Physicians. National Sentinel Stroke Audit, Phase II (clinical audit) 2008. London: Clinical Effectiveness and Evaluation Unit, Royal College of Physicians; 2009.

[17] Hart S, Morris R. Screening for depression after stroke: an exploration of professionals’ compliance with guidelines. Clin Rehabil 2008;22: 60-70.

[18] Bennett HE, Lincoln N. Potential screening measures for depression and anxiety after stroke. Int J Ther Rehabil 2006;13: 401-6.

[19] Lincoln NB, Kneebone II, Macniven JAB, \& Morris R. Psychological management of stroke. Chichester UK: Wiley; 2012.

[20] Berg A, Lönnqvist J, Palomäki H, \& Kaste M. Assessment of depression after stroke: a comparison of different instruments. Stroke 2009;40: 523-9.

[21] Kneebone I. Post-stroke depression and the non mental-health therapist. Br J Ther Rehabil 1999;6: 476-81.

[22] Kneebone I, Baker J, O’Malley H. Screening for depression after stroke: developing protocols for the occupational therapist. Brit J Occup Ther 2010;73: 71-6.

[23] Lightbody CE, Baldwin R, Connolly M, Gibbon B, Jawaid N, Leathley M, Sutton C, Watkins, CL. Can nurses help identify patients with depression following stroke? A pilot study using two methods of detection. J Adv Nurs 2007;5: 505-12.

[24] Jorm AF. Does old age reduce the risk of anxiety and depression? A review of epidemiological studies across the adult life span. Psychol Med 2000;30: 11-22.

[25] Palmer BW, Jeste DV, Sheikh JI. Anxiety disorders in the elderly: DSM-IV and other barriers to diagnosis and treatment. J Affect Disord 1997;46: 183-90.

[26] Spitzer RL, Kroenke K, Williams JBW. Validation and utility of a self-report version of PRIME-MD: the primary care study. J Am Med Assoc 1999;282: 1737-44.

[27] American Psychiatric Association. Diagnostic and statistical manual of mental disorders. ( $4^{\text {th }}$ ed.). Washington DC: Author; 1994.

[28] Williams LS, Brizendine EJ, Plue L, Bakas T, Tu W, Hendrie H, Kroenke KK. Performance of the PHQ-9 as a screening tool for depression after stroke. Stroke 2005;36: 635-638. 
[29] Zigmond AS, Snaith RP. The Hospital Anxiety and Depression Scale. Acta Psychiatrica Scand 1983;67: 361-70.

[30] Sagen U, Vik TG, Moum T, Morland T, Finset A, Dammen T. Screening for anxiety and depression after stroke: comparison of the HADS and the Montgomery and Asberg Depression Rating Scale. J Psychosom Res 2009;67: 325-32.

[31] Johnson, G, Burvill PW, Anderson CS, Jamrozik K, Stewart-Wynne EG, Chakera, T.MH. Screening instruments for depression and anxiety after stroke: experience in the Perth community stroke study. Acta Psychiatrica Scand 1995;9: 252-7.

[32] Sutcliffe LM, Lincoln NB. The assessment of depression in aphasic stroke patients: the development of the Stroke Aphasic Depression Questionnaire. Clin Rehabil 1998;12: 506-13.

[33] Leeds L, Meara RJ, Hobson JP. The utility of the Stroke Aphasia Depression Questionnaire (SADQ) in a stroke rehabilitation unit. Clin Rehabil 2004;18: 228-31.

[34] Kogan JN, Edelstein BA, McKee, DR. Assessment of anxiety in older adults: current status. J Anxiety Disord 2000;14: 109-32.

[35] Watanabe Y. Fear of falling among stroke survivors after discharge from inpatient rehabilitation. Int J Rehabil Res 2005;2: 149-52.

[36] Wetherell JL, Le Roux H, Gatz M. DSM-IV criteria for generalized anxiety disorder in older adults: distinguishing the worried from the well. Psychol Aging 2003;18: 622-7. 
If the patient scores $\geq 1$ on item 9, or a total of 10 or more, on the PHQ9, then please ask the following questions:

So far the questions I have asked suggest you have been feeling quite low?

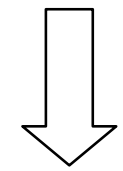

How bad have things got for you?

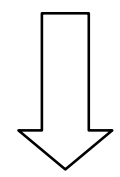

Did it ever get to the point where you wanted to end it all?<smiles>C1CCCCC1</smiles>

Have you seriously considered taking your own life?

$\underline{\text { YES }}$

(PLEASE CIRCLE THE PATIENTS RESPONSE)

Figure 1. Questioning about suicide 
Figure 2. Screening protocol for those without a significant cognitive or communication disability. 
All screens should be done during the first 4 weeks of contact with a patient in the community.*

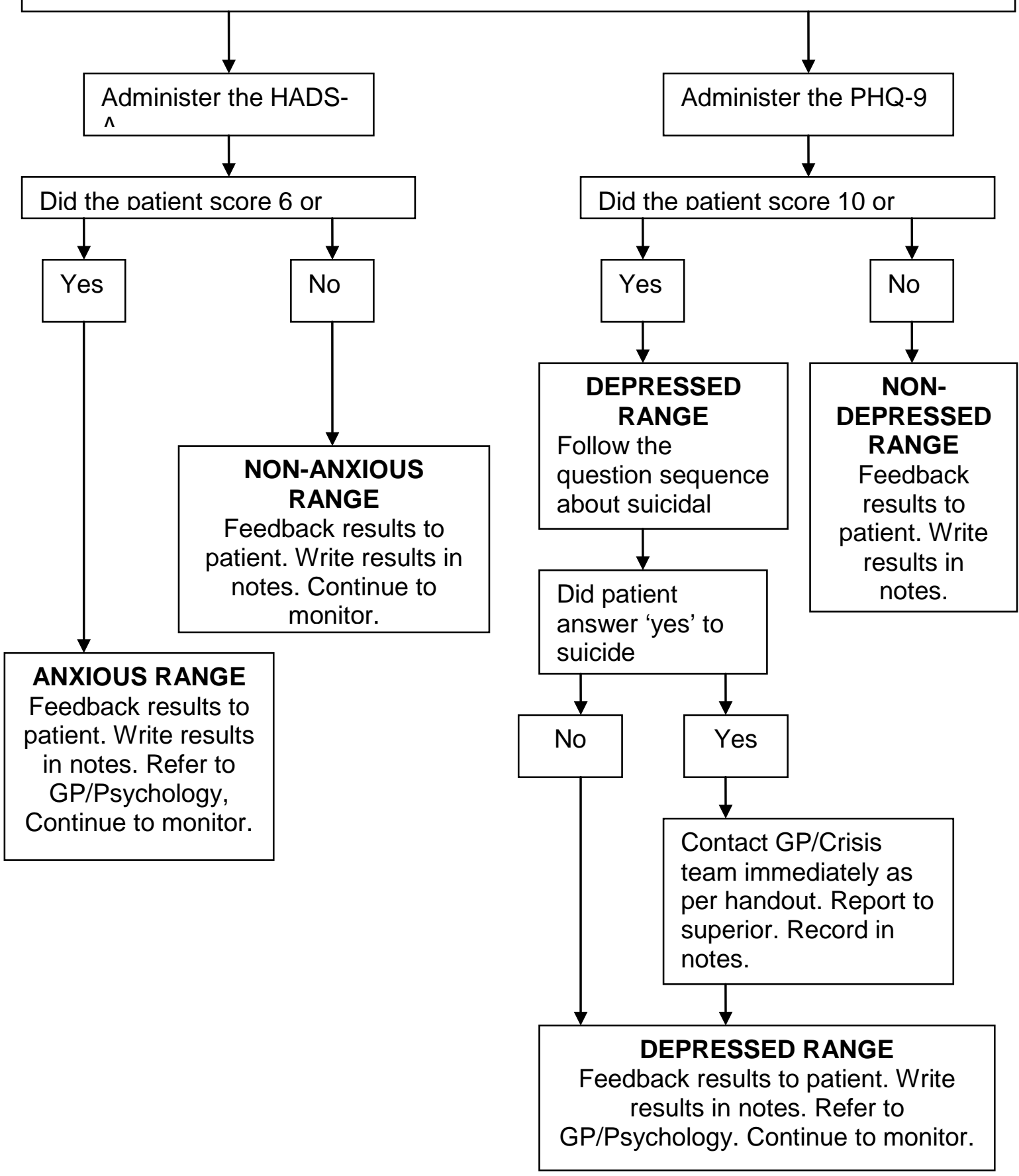

Note. HADS-A = Hospital Anxiety and Depression Scale, Anxiety Scale, PHQ-9 = Patient Health Questionnaire $-9, \mathrm{GP}=$ General Practitioner.* Or receives a score $\geq 1$ on item 9 of the PHQ-9; * If serious suicidal ideas are not detected, the patient is considered as being in the non-depressed range. 
Figure 3. Screening protocol for those with a significant cognitive or communication disability. 


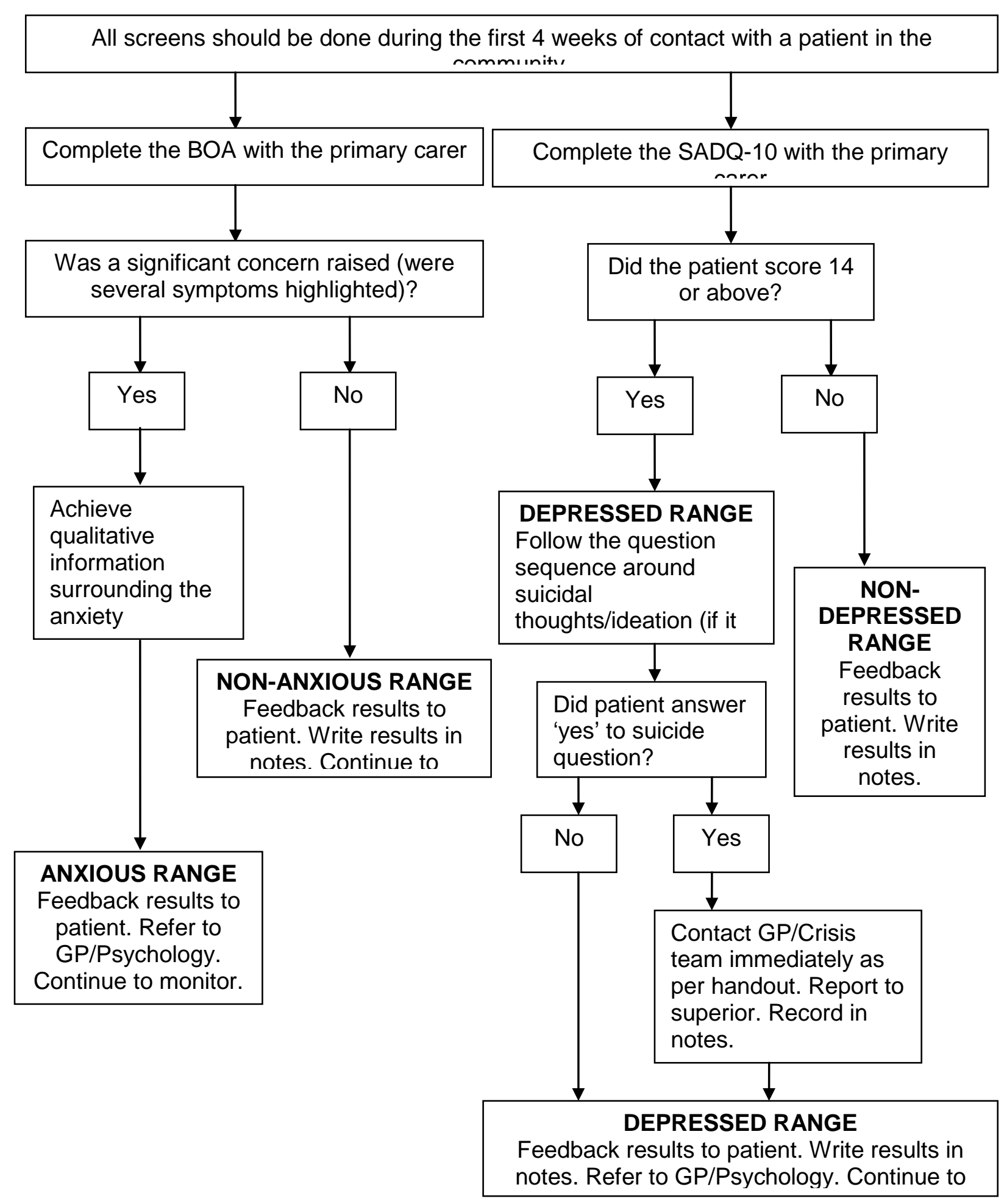

Note: $\mathrm{BOA}=$ Behavioural Outcomes of Anxiety, SADQ -10 = Stroke Aphasic Depression Questionnaire, 10-item Community Version, GP = General Practitioner family doctor. 


\begin{tabular}{|c|c|c|}
\hline Instrument & Description & $\begin{array}{l}\text { Cut-offs for use with } \\
\text { people who have had a } \\
\text { stroke }\end{array}$ \\
\hline $\begin{array}{l}\text { PHQ-9, Patient } \\
\text { Health } \\
\text { Questionnaire, } \\
\text { 9-item[25] }\end{array}$ & $\begin{array}{l}\text { The PHQ-9 asks patients to rate on a } \\
0 \text {, 'not at all' to } 3 \text {, 'nearly every day' } \\
\text { scale, how often they have been } \\
\text { bothered by problems such as 'Feeling, } \\
\text { down, depressed or hopeless', over the } \\
\text { past } 2 \text { weeks. Scores range from } 0 \text { to } \\
27 \text {. It is recommended for use with } \\
\text { post-stroke patients by the Royal } \\
\text { College of Physicians [14] }\end{array}$ & $\begin{array}{l}10 \text { or more, sensitivity = } \\
0.91 \text {, specificity }=0.89 \text { for } \\
\text { major depression. } \\
\text { Sensitivity }=0.78 \text { and } \\
\text { specificity }=0.96 \text { for any } \\
\text { other depression diagnosis } \\
{[27]}\end{array}$ \\
\hline $\begin{array}{l}\text { HADS-A, } \\
\text { Hospital } \\
\text { Anxiety } \\
\text { Depression } \\
\text { Scale-Anxiety } \\
\text { 7-item [28] }\end{array}$ & $\begin{array}{l}\text { HADS-A items are endorsed on a } \\
\text { range from } 0 \text { to } 3 \text {, to indicate how } \\
\text { someone has been feeling over the } \\
\text { past week. Scores for the anxiety } \\
\text { dimension range from } 0 \text { to } 21 \text {. The } \\
\text { HADS-A forms part of the HADS, which } \\
\text { also includes a depression scale. It was } \\
\text { originally designed for use with } \\
\text { hospitalised, medically ill patients. }\end{array}$ & $\begin{array}{l}6 \text { or more, sensitivity }=0 \text {. } \\
80, \text { and specificity }=0.42 \\
{[30] \text {. }}\end{array}$ \\
\hline $\begin{array}{c}\text { SADQ-10, } \\
\text { Stroke Aphasic } \\
\text { Depression } \\
\text { Questionnaire } \\
\text { 10-item } \\
\text { community } \\
\text { version [31] }\end{array}$ & $\begin{array}{l}\text { The SADQ-10 is completed by a } \\
\text { patients' carer, based on his/her } \\
\text { observations of behaviour. Items such } \\
\text { as "Does he/she avoid eye contact } \\
\text { when you talk to him/her?" are rated } \\
\text { across } 4 \text { levels from 'Often' (rated } 3 \text { ) to } \\
\text { 'Never' (rated 0). Scores range from } 0 \\
\text { to } 30 \text {. The SADQ-10 was designed for } \\
\text { community use with patients who have } \\
\text { cognitive and communication } \\
\text { difficulties. }\end{array}$ & $\begin{array}{l}14 \text { or more, sensitivity = } \\
0.7 \text { and specificity }=0.71 \\
{[32] \text {. }}\end{array}$ \\
\hline $\begin{array}{c}\text { BOA, } \\
\text { Behavioural } \\
\text { Outcomes } \\
\text { of Anxiety, 10- } \\
\text { item }\end{array}$ & $\begin{array}{l}\text { The BOA was designed specifically as } \\
\text { part of this project in the absence of } \\
\text { any alternative. It and has not yet been } \\
\text { validated. A clinician completes it, } \\
\text { ideally with help of the patient's carer. } \\
\text { As can be seen in table } 2 \text {, it is based } \\
\text { on observations of behaviour with a } \\
\text { response format similar to the } \\
\text { SADQ10. The BOA was developed to } \\
\text { screen for anxiety in patients with } \\
\text { cognitive and communication } \\
\text { difficulties. }\end{array}$ & $\begin{array}{l}\text { The BOA does not have a } \\
\text { cut-off. A significant } \\
\text { concern is raised if the } \\
\text { BOA highlights several } \\
\text { symptoms. } \\
\text { information should be } \\
\text { gathered to support the } \\
\text { information from this } \\
\text { instrument. }\end{array}$ \\
\hline
\end{tabular}

Table 1. Instruments for use in screening for depression and anxiety after stroke, in the community 
Table 2. Behavioural Outcomes of Anxiety (BOA).

1. Does he/she appear particularly tense or on edge? [27]

Often

Sometimes

Rarely

Never

2. Does he /she have a strained face?

Often

Sometimes

Rarely

Never

3. Does he/she avoid activities or social engagements without good reason? [27]

\begin{tabular}{|c|c|c|c|}
\hline Often & Sometimes & Rarely & Never \\
\hline \multicolumn{4}{|c|}{ 4. Does he/she appear fearful of falling? [35] } \\
\hline Often & Sometimes & Rarely & Never \\
\hline \multicolumn{4}{|c|}{ 5. Does he/she have trouble falling or staying asleep? [27] } \\
\hline Often & Sometimes & Rarely & Never \\
\hline \multicolumn{4}{|c|}{ 6. Is he/she jumpy or easily startled? } \\
\hline Often & Sometimes & Rarely & Never \\
\hline
\end{tabular}

7. Is he/she restless or constantly on the move (e.g. do they pace)? [34]

Often

Sometimes

Rarely

Never

8. Is he/she easily tired? $[27,36]$

Often

Sometimes

Rarely

Never

9. Does he/she appear anxious? [26]

Often

Sometimes

Rarely

Never

10. Does he/she appear to panic, or have unusual episodes of breathlessness or hyperventilation?

Often

Sometimes

Rarely

Never 
